\title{
Concentrated Solution Dosage Form
}

National Cancer Institute

\section{Source}

National Cancer Institute. Concentrated Solution Dosage Form. NCI Thesaurus. Code C42898.

A concentrate which is usually diluted prior to administration and exists as a solution in its final form. 